Research Article

\title{
Sensitivity of Multistage Fill Slope Based on Finite Element Model
}

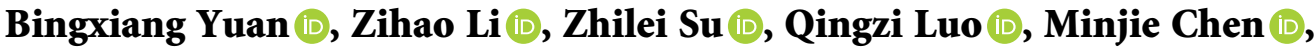 \\ and Zuqing Zhao \\ School of Civil and Transportation Engineering, Guangdong University of Technology, Guangzhou 510006, China \\ Correspondence should be addressed to Qingzi Luo; lqz1986@gdut.edu.cn
}

Received 10 November 2020; Revised 3 March 2021; Accepted 10 March 2021; Published 25 March 2021

Academic Editor: Jian Ji

Copyright (C) 2021 Bingxiang Yuan et al. This is an open access article distributed under the Creative Commons Attribution License, which permits unrestricted use, distribution, and reproduction in any medium, provided the original work is properly cited.

\begin{abstract}
Based on the strength reduction method, the laws of slope displacement and the changing positions of the sliding surface during the filling process are studied. The model of multistage fill slope is established by the finite element software PLAXIS. The difference is compared between the slope with no reinforcement and with reinforcement under the same working condition. Sensitivity analysis is carried out from two aspects which are internal factors and external factors. The finite element analysis shows that the settlement of the multistage fill slope with no reinforcement is mainly concentrated on the right side of the slope and gradually decreases with the increase of the filling height. The position of the sliding outlet is located at the joint of the first and the second grade of the slope. The effect of the reinforcement on the sliding surface is ideal. It is obvious that the reinforcement can supply the slope with a better position of the sliding surface, which is beneficial to the stability of the slope. The sensitivity analysis shows that unit weight, ratio of slope, and height of each grade are negatively correlated with the safety factor. At the same time, the platform width, cohesion, and internal friction angle are positively correlated with the safety factor. The internal friction angle has the greatest influence on the stability of the slope. Besides, the platform width and the height of each grade should be controlled at about $4 \mathrm{~m}$. The sensitivity analysis provides a reference for the design of the multistage filling slope.
\end{abstract}

\section{Introduction}

Slope stability analysis has always been an important issue in the field of geotechnical engineering, which is the key research object of geotechnical workers [1]. With the advancement of urban construction, suburban engineering construction is in full swing, and more and more high fill slopes appear [2]. The slope of multistage filling is complex [3], and many factors such as unit weight, cohesion, and internal friction angle affect its stability [4-7]. For a specific multistage filling slope, the study of the sensitivity of its stability to various factors will help to identify the most dangerous factors, so as to avoid risks in practical engineering.

For filling slope, some scholars pay attention to the influence of filling materials on slope stability and put forward different slope reinforcement methods. For example, the prestressed anchor can improve the stress distribution of the slope [8]. Anchored geosynthetics can improve slope stability and deformation behavior [9]. In addition, the antislide pile [10-14] and soil nail [15] are proved to be good slope reinforcement methods.

Many slope stability analysis methods have been proposed [16-21], which are divided into traditional analysis methods and numerical analysis methods [22]. In view of the powerful computing power of computers, the numerical analysis method is widely used [23-27], such as the finite element method and discrete element method. The safety factor is usually used to quantify slope stability. At present, it is common to integrate the strength reduction method (SRM) into finite element software to evaluate slope stability. In this method, the soil strength parameters $(\tan \varphi)$ and $(c)$ decrease continuously until the structure is destroyed. The most classic example of applying SRM to finite element numerical simulation is the evaluation of homogeneous slope stability in Dawson's paper [28]. He analyzed a wide range of tilt angles, soil friction angles, and pore pressure coefficients. The results obtained from the strength reduction technique are in good agreement with those predicted by traditional methods. Since then, the method has been 
successfully applied to dam stability analysis and tunnel stability analysis.

The sensitivity analysis of slope is helpful to study the main factors causing the deterioration of slope stability [29-32]. FLAC3D is used to establish the slope model, and it is found that the freeze-thaw cycle is the sensitive factor of slope stability in the plateau area [33]. Controlling the freeze-thaw cycle is beneficial to the stability of the slope in the plateau area. Sadarviana pointed out that the safety factor of the slope is very sensitive to the location of groundwater level, and the change of groundwater level should be paid enough attention to in the process of slope monitoring [34].

In the existing research, there are still some deficiencies in the stability comparative analysis and sensitivity analysis of multistage filling slope before and after reinforcement. In this paper, the finite element software PLAXIS is used to study the regulation of displacement of the slope and the regulation of the location of sliding surface during the filling process of multistage fill slope. The difference between the slope with and without reinforcement under the same working conditions are compared and summarized. In addition, the combined reinforcement of frame beam, anchor, and antislide pile is evaluated to provide a reference for practical slope engineering. Based on the sensitivity analysis method, the sensitivity analysis of the internal and external factors (internal friction angle, cohesion, slope ratio, etc.) of the slope is carried out according to the specific conditions. Finally, the most sensitive factors are found, and suggestions for the actual slope construction and protection are put forward.

\section{Finite Element Analysis}

Since the safety factor of the slope cannot directly be obtained by the finite element method to evaluate its stability, Zienkiewicz [35] proposed the strength reduction method and defined the strength reduction factor as the ratio of the shear strength of the slope to the shear stress generated by the external load in the slope. Further, the strength reduction factor is defined as the safety factor of the slope when the slope reaches the critical failure state.

\subsection{Establishment of Finite Element Model}

2.1.1. Parameters of Model Material. The original foundation and the fill soil of the multistage fill slope is silty clay. To simplify the model [36], the soil layer is simplified, and its parameters are shown in Table 1 . The parameters of frame beam, anchor, and antislide pile are shown in Table 2. The strength grade of concrete is $\mathrm{C} 30$. The antislide pile, of which the diameter is $1 \mathrm{~m}$, the horizontal distance is $2.5 \mathrm{~m}$, the length is $8 \mathrm{~m}$, is made of Q235 steel. The full-length bonded anchor includes three types of length: $10 \mathrm{~m}, 12 \mathrm{~m}$, and $15 \mathrm{~m}$. The diameter of the borehole is $2.5 \mathrm{~m}$. Its dip is valued as $15^{\circ}$, and its distance of horizontal and vertical is $2.5 \mathrm{~m}$.

2.1.2. Model Establishment. The multistage fill slope is composed of two parts: the fill soil and the original foundation. The model area includes the slope soil and the soil within a certain influence range around the slope soil. Model size meets the following conditions, the left boundary of the slope is 1.5 times the slope height from the foot of the slope, the right boundary of the slope is 2.5 times slope height from the foot of the slope, and the slope top is 2 times the slope height from the lower boundary of the slope. The purpose of this method is to eliminate the boundary effect and improve the calculation accuracy. The lower part of the model is the original foundation, and the upper part is the fill soil. The horizontal constraint is added to the left and right boundary of the model, and the fixed constraint is added to the bottom of the model. The section diagram is shown in Figure 1.

Based on a stable triangulation program, the finite element mesh is generated by PLAXIS automatically [37]. 15node triangular elements are used to form unstructured meshes. This kind of mesh is performing better than the regular mesh in numerical calculation. The meshes are set denser in some key areas to achieve higher computational accuracy [38]. The partition of finite element mesh is shown in Figure 2.

After artificial filling, the stress in the slope is redistributed due to the loading of soil weight, and the slope will be deformed and destroyed [39, 40]. As shown in Figure 3, the principal stress trajectory near the slope surface is deflected. The maximum principal stress is nearly parallel to the slope surface, the minimum principal stress is nearly orthogonal to the slope surface, and the slope gradually restores to the approximate initial stress state. It is consistent with the stress redistribution law of the slope. Thus, the software is feasible and effective on this issue.

2.2. Working Condition. The original foundation layer is 31 meters thick. The slope is 28 meters high, divided into seven layers of fill soil. As shown in Figure 4, there are four grade slopes. The analysis steps are as follows: the initial stress of the original foundation is balanced at first, which can simulate the consolidation of the natural slope and improve the calculation accuracy of the model; then, the fill soil is loaded layer by layer; finally, the settlement regulation and failure trend of the slope are analyzed. The specific construction conditions 1 to 8 are corresponding to (1) to (8) in Figure 4, respectively.

2.3. Results of the Analysis. After the numerical simulation analysis of 8 working conditions, the vertical displacement nephogram of each working condition is obtained. As shown in Figure 5, the frame beam, anchor, and antislide pile in the nephogram are inactive when they are shown as thin lines; conversely, they are shown as thick lines. The settlement value in the nephogram is an accumulative procedure.

2.3.1. Regulation of Settlement of Slope during Graded Filling without Reinforcement. As shown in Figure 6, the main settlement occurs in the filling part of the slope. The final cumulative settlement is $49.1 \mathrm{~cm}$, and the maximum settlement of the whole slope mainly occurs on the right side of the slope where the altitude is higher. Along the cross section 
TABle 1: Parameters of multistage fill slope.

\begin{tabular}{lccccc}
\hline Mechanical parameters of soil & $\begin{array}{c}\text { Unit weight } \\
\left(\mathrm{kN} / \mathrm{m}^{3}\right)\end{array}$ & Cohesion $(\mathrm{kPa})$ & Internal friction angle $\left(^{\circ}\right)$ & Poisson's ratio & Compression modulus $(\mathrm{MPa})$ \\
\hline Fill soil & 19 & 12.26 & 30 & 0.18 & 6 \\
Original foundation & 19 & 26 & 30 & 0.16 & 8 \\
\hline
\end{tabular}

TABle 2: Parameters of frame beam, anchor, and antislide pile.

\begin{tabular}{lccc}
\hline Structure & Dimensions $(\mathrm{m})$ & Equivalent bending stiffness $\left(\times 10^{4} \mathrm{kN} \cdot \mathrm{m}^{2} / \mathrm{m}\right)$ & Equivalent axial stiffness $\left(\times 10^{5} \mathrm{kN} / \mathrm{m}\right)$ \\
\hline Frame beam & $0.3 * 0.3$ & 1 & 7.5 \\
Antislide pile & $d=1, l=8$ & 1 & 7.5 \\
Anchor & $l=10,12,15$ & - & 2.0 \\
\hline
\end{tabular}

Note: $d$ is the diameter and $l$ is the length.

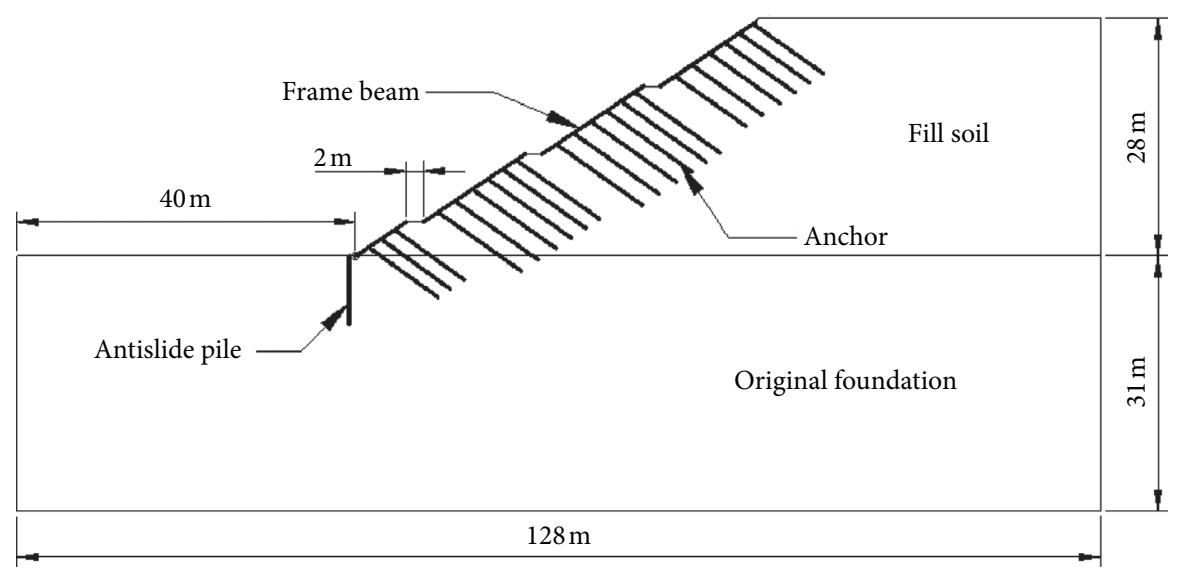

FIgURE 1: The diagram of multistage fill slope with frame beam and anchor reinforced.

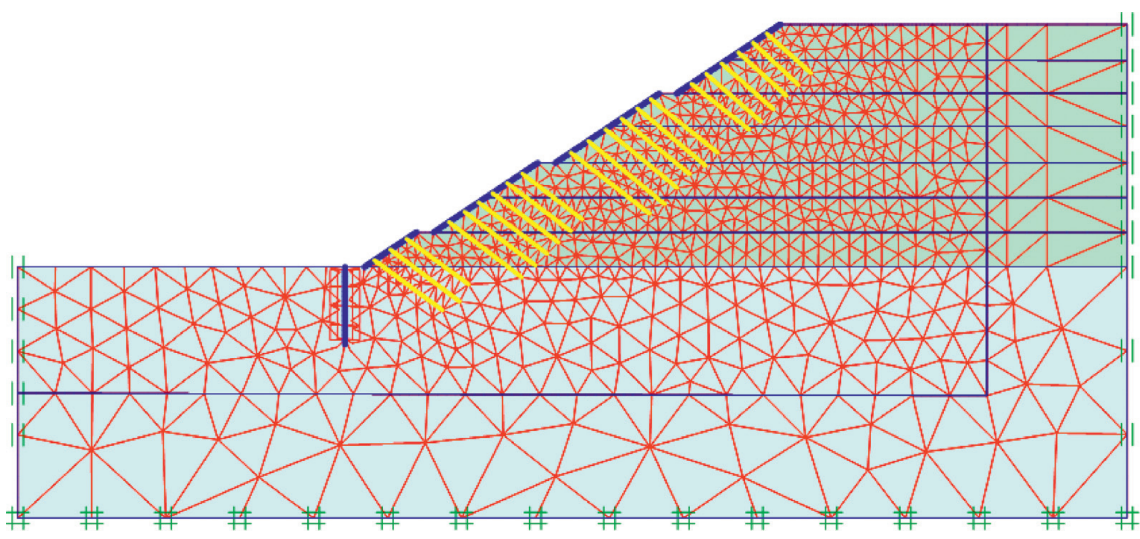

FIgURE 2: The partition of finite element mesh.

of the slope right to left, the settlement deformation gradually decreases, and the displacement is 0 at a certain depth from the foot of the slope. The main reason is that the filling load diffusing in the foundation is limited. The farther away from the loading point, the less affected. The uplift phenomenon occurred at the left boundary of the slope with the continuous loading, and the maximum displacement reached $2.3 \mathrm{~cm}$.

The results of the analysis show that the maximum vertical displacement of the first-stage filling is $4.55 \mathrm{~cm}$, the second-stage filling is $16.1 \mathrm{~cm}$, and the third-stage filling is $31.14 \mathrm{~cm}$. Further, the settlement of the second-stage filling increases rapidly, which is about 3.2 times larger than that of the last stage. The settlement after the third stage loading is about $50 \%$ higher than that of the last stage, and the settlement after the fourth stage loading is about $51 \%$ higher than that of the last stage. In other words, with the increase of filling height, the increment of vertical settlement deformation of slope gradually slows down and tends to be stable. 


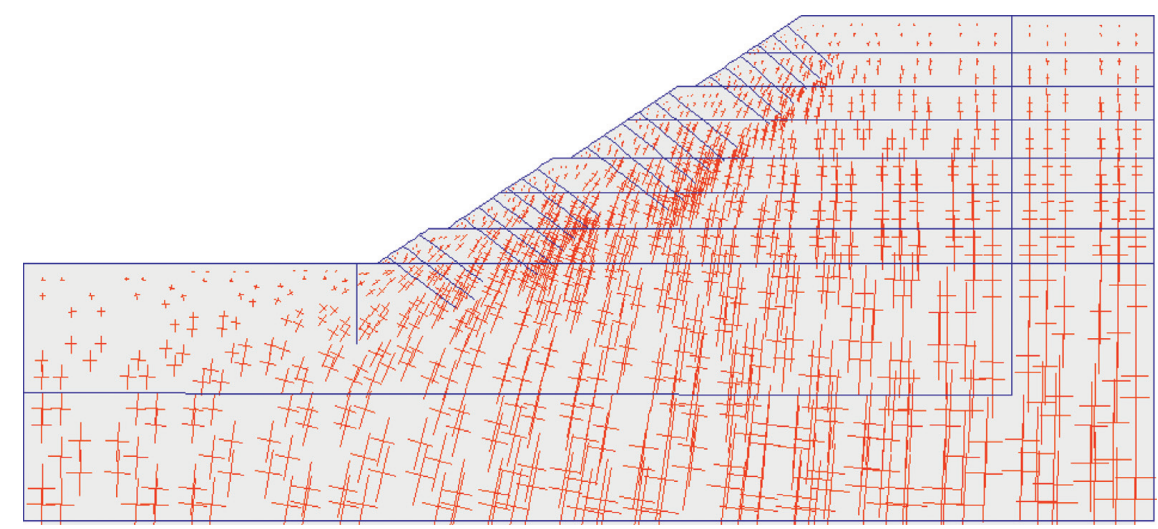

Figure 3: The effective stress distribution when the slope construction conditions are finished.

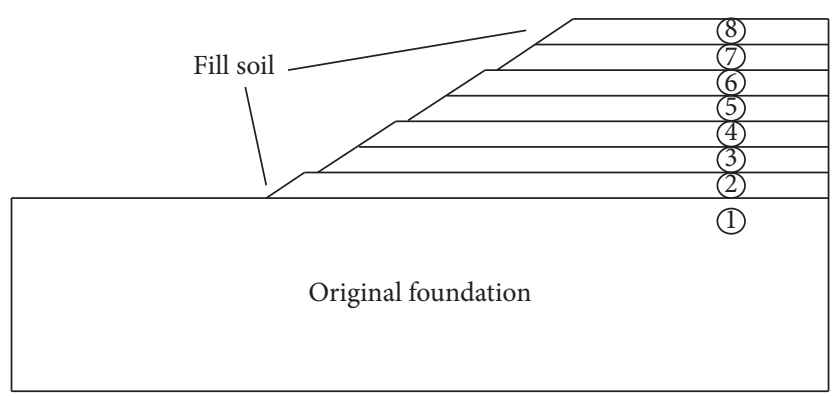

FIgURE 4: The diagram of construction conditions of multistage fill slope.

2.3.2. Regulation of Horizontal Displacement of Slope during Staged Filling without Reinforcement. The horizontal displacement of the slope calculated by the finite element method at different filling stages is shown in Figure 7 . The results of the calculation show that the maximum horizontal displacement at the top of the slope is $52.25 \mathrm{~mm}$. The horizontal displacement is larger near the slope surface and the lower part of the slope foot, and the main direction is to the left slope foot.

\subsubsection{Regulation of Position of Slope Sliding Surface during} Staged Filling Process without Reinforcement. As shown in Figure 8 , the shear strain increment predicts the possible failure mode of slope and reflects the change of slope slip surface. When the second-stage filling is completed, the shear strain at the foot of the slope is large, and the sliding outlet is likely to appear at this position. When the thirdstage filling is completed, a small area sliding surface appeared in the slope. Further, when the fourth-stage filling is completed, the shear strain increment is large, and the slope appears as a complete sliding surface, which is about $4.5 \mathrm{~m}$ on average below the slope. The sliding outlet is near the connecting position between the first stage slope and the second-stage slope.

2.3.4. Comparison of Slope Displacement during Filling Process between the Reinforcement and Unreinforcement Conditions. The settlement and failure trend of multistage fill slope under reinforcement conditions are also analyzed by PLAXIS. Due to limited space, only partial working conditions are contrasted.

As shown in Figure 9, the maximum settlement at the top of the slope with reinforcement measures is $46.1 \mathrm{~cm}$. Compared with the maximum settlement of $49.1 \mathrm{~cm}$ at the top of the slope without reinforcement in Figure 6(d), it reveals that the control effect of the reinforcement structure on the slope settlement is not obvious.

As shown in Figure 7(b), the horizontal displacement to the right side is easy to occur near the upper surface of the second-stage slope when the slope is without reinforcement. When the slope is not reinforced, the stress of the soil in the right boundary is greater than the stress of the foot of the slope at the same height, so the vertical settlement deformation generated during the filling process is mainly concentrated on the right side of the slope body, resulting in the horizontal displacement in the right direction in the area of the top of the slope just after filling. The maximum displacement is $2.5 \mathrm{~cm}$. After the slope is reinforced, as shown in Figure 10, the horizontal displacement on the right side significantly reduces, and the maximum displacement is $1.6 \mathrm{~cm}$, which is $36 \%$ less than that without reinforcement. The horizontal displacement of the original foundation to the left also significantly reduces, and the maximum horizontal displacement is reduced to $0.8 \mathrm{~cm}$, which is $200 \%$ lower than the maximum displacement without reinforcement. Therefore, the reinforcement effect is beneficial to control the horizontal displacement during the slope filling process and improve the stability of the high fill slope. 


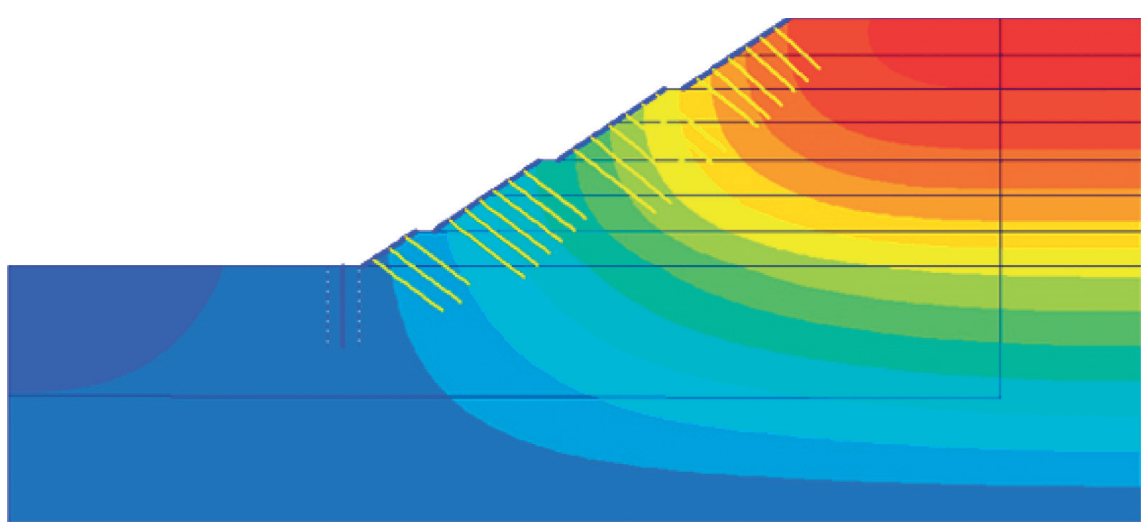

(a)

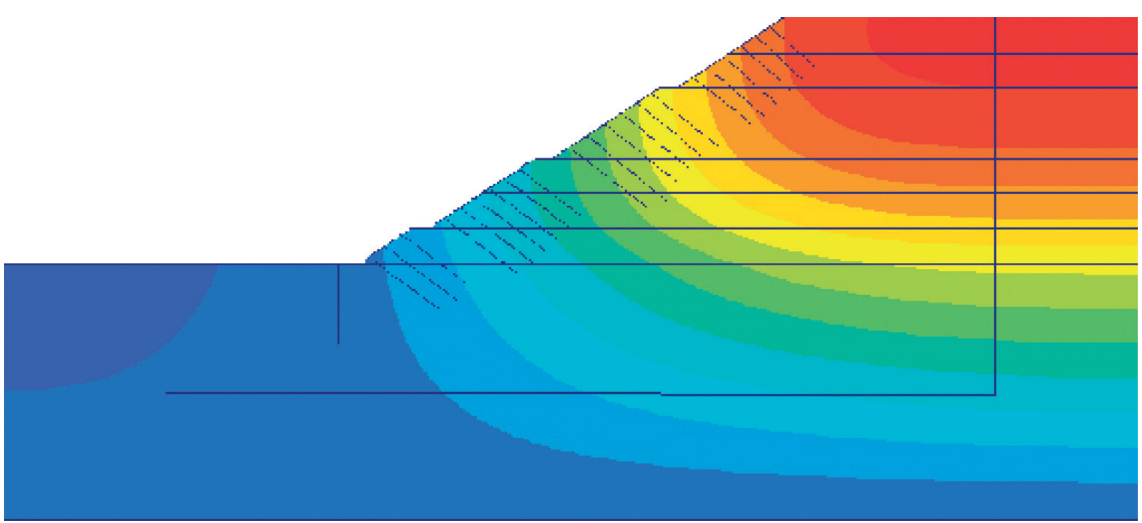

(b)

FIGURE 5: Vertical displacement nephogram when the reinforcement active or inactive. (a) Reinforcement active. (b) Reinforcement inactive.

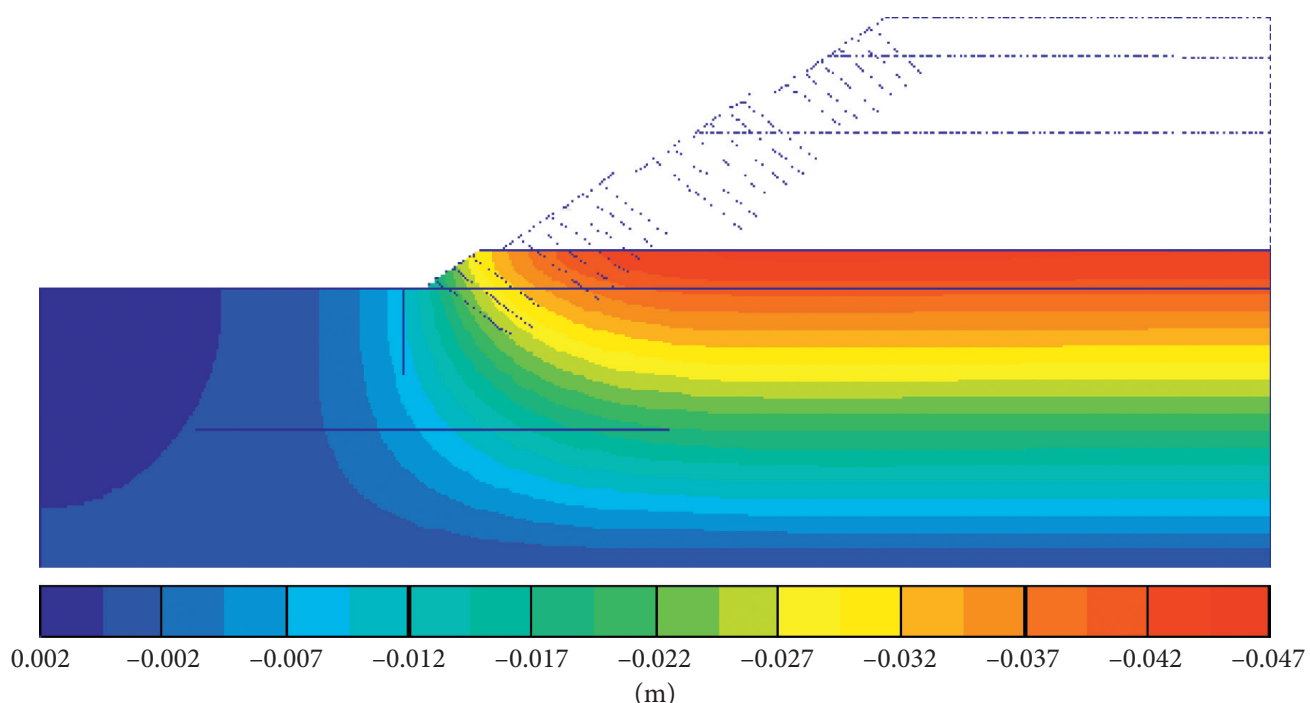

(a)

Figure 6: Continued. 


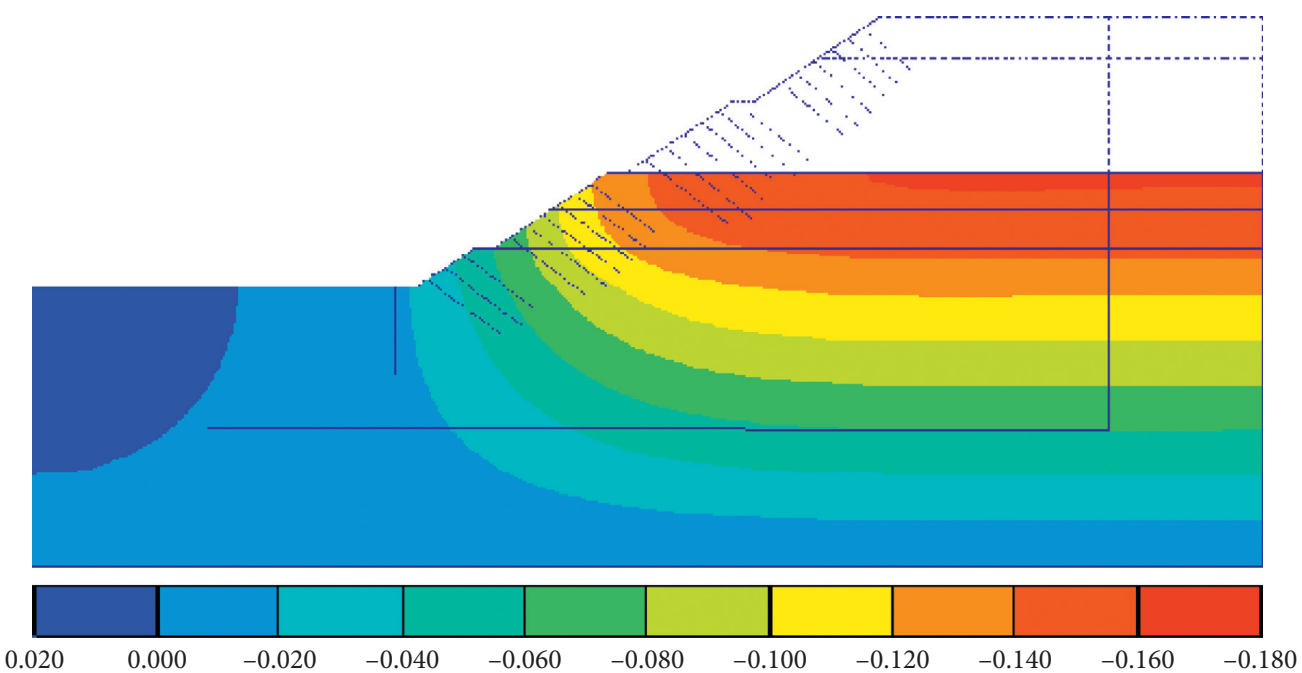

(m)

(b)

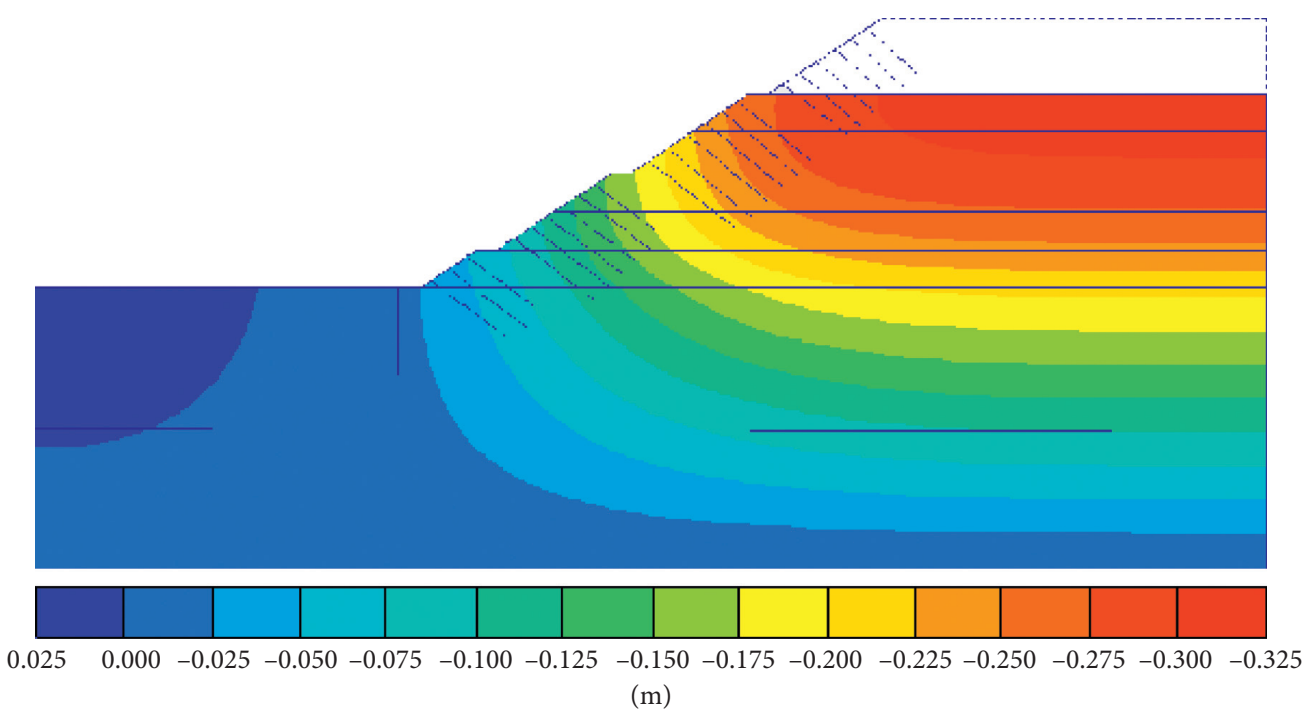

(c)

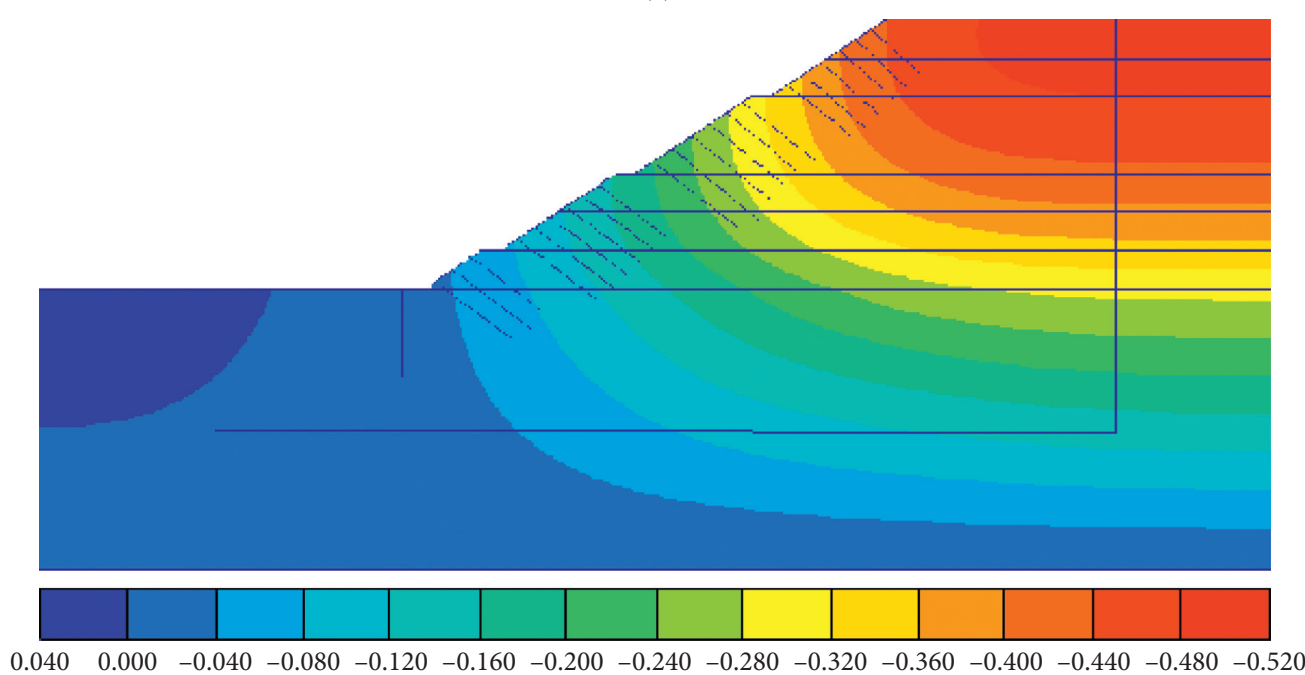

(m)

(d)

FIgURE 6: Vertical displacement nephogram with the construction conditions of slope. (a) Working condition 2. (b) Working condition 4. (c) Working condition 6. (d) Working condition 8. 


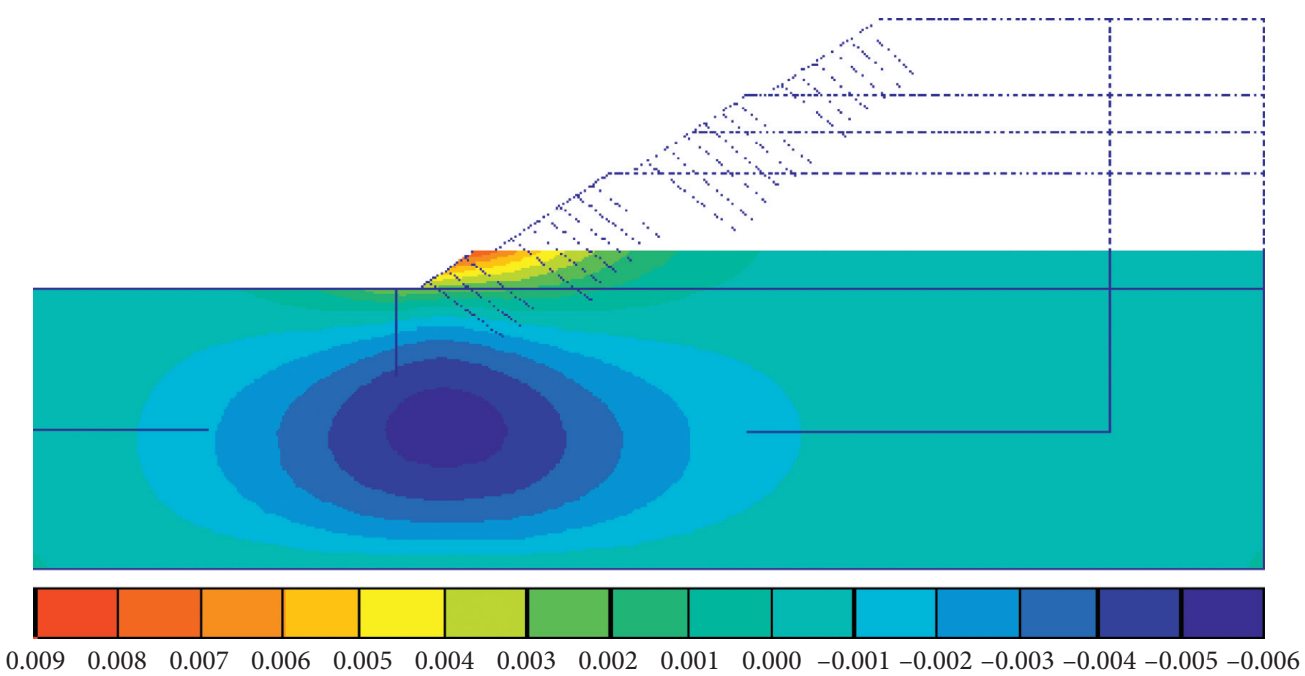
(m)

(a)

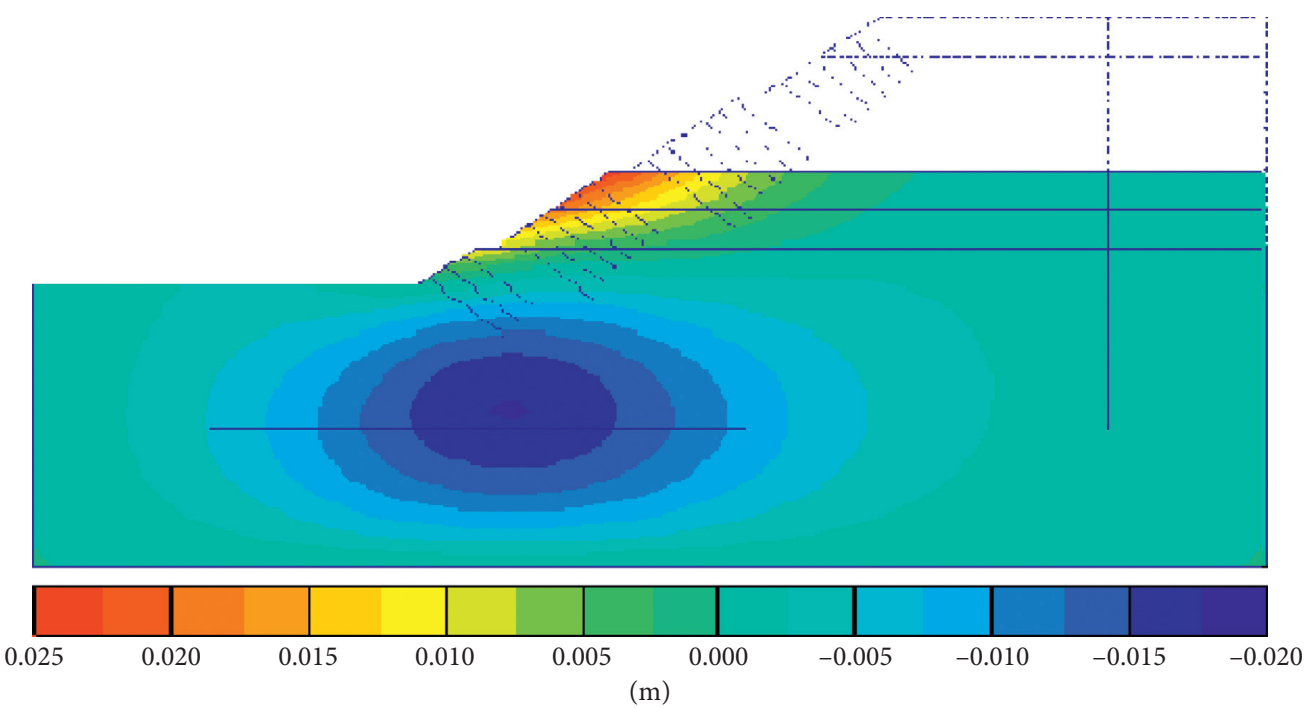

(b)
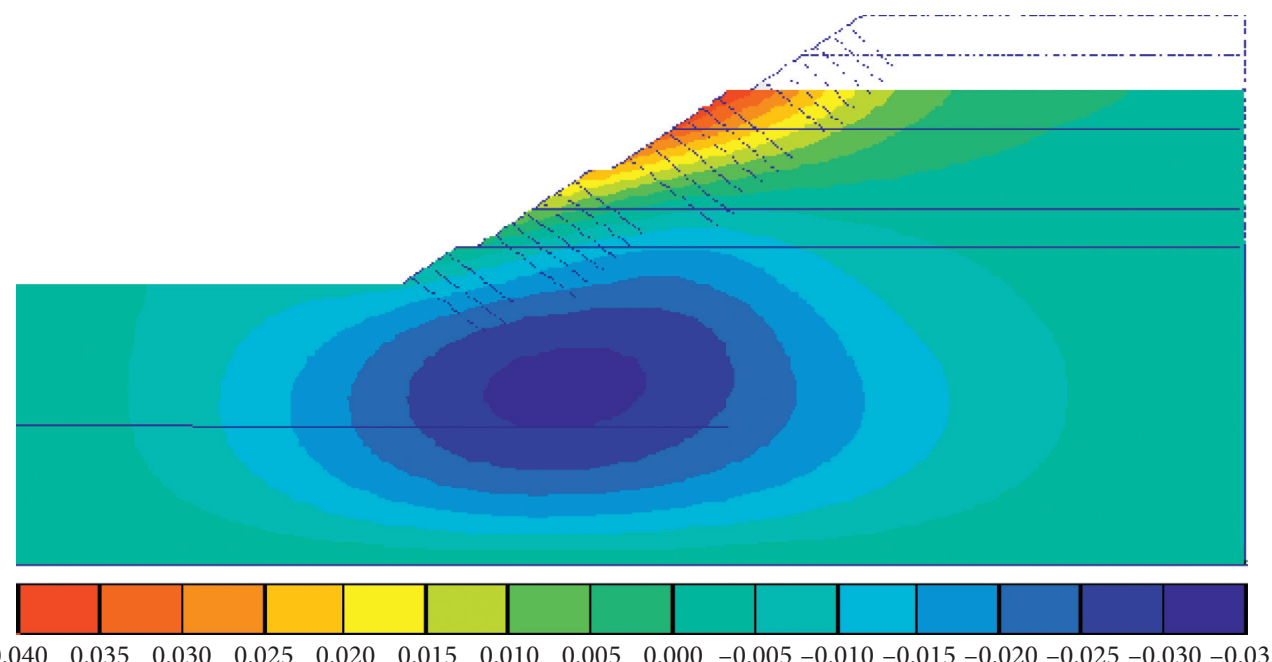

(m)

(c)

FIgURE 7: Continued. 


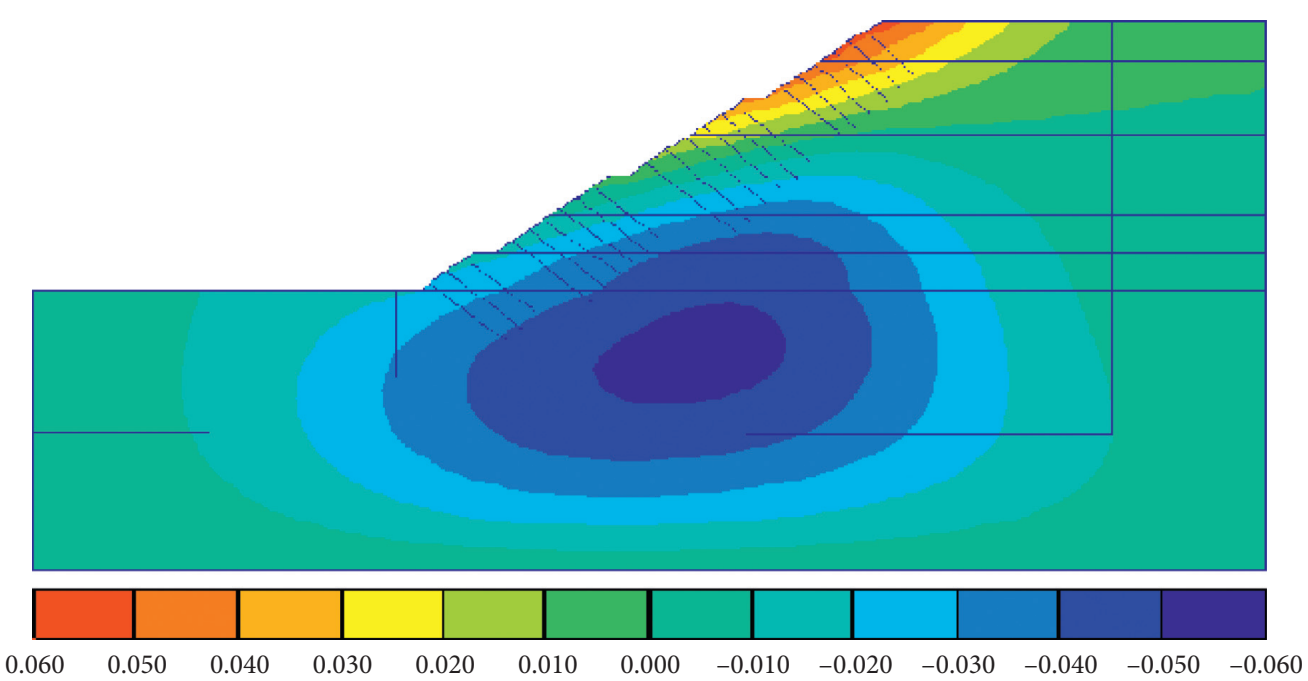

(m)

(d)

FIGURE 7: Horizontal displacement nephogram with the construction conditions of slope. (a) Working condition 2. (b) Working condition 4. (c) Working condition 6. (d) Working condition 8.

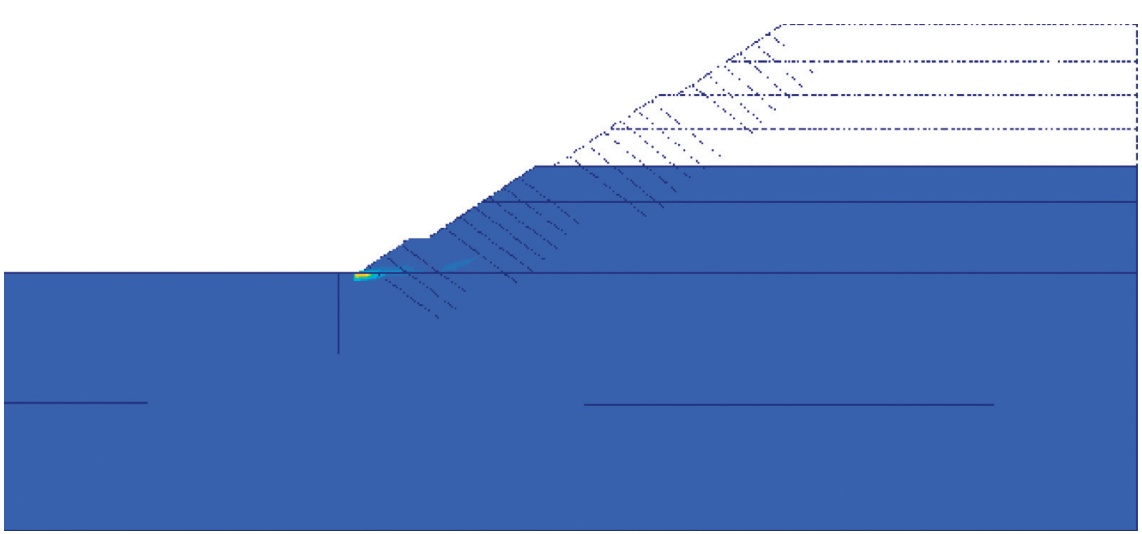

(a)

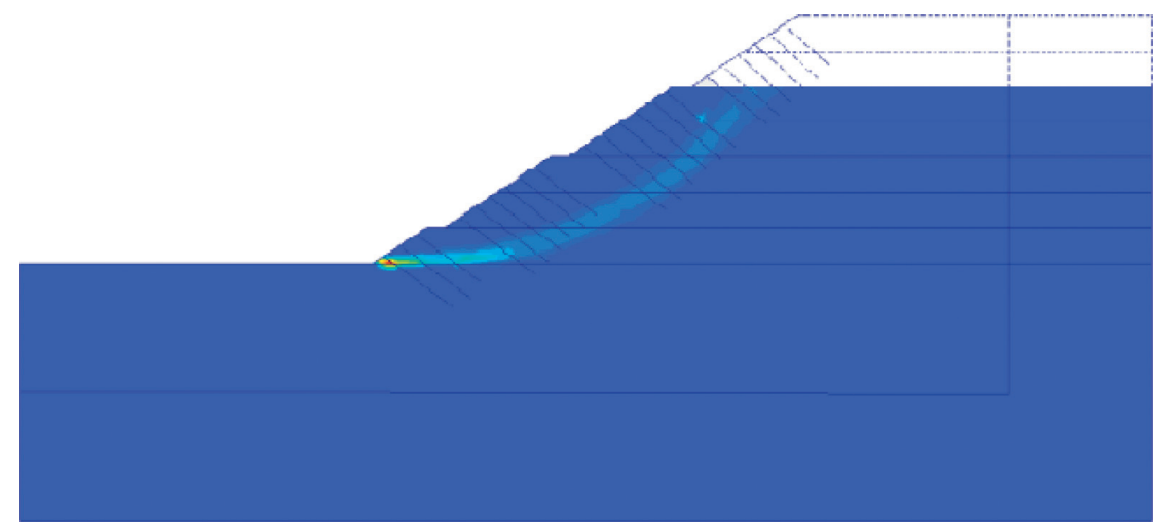

(b)

Figure 8: Continued. 


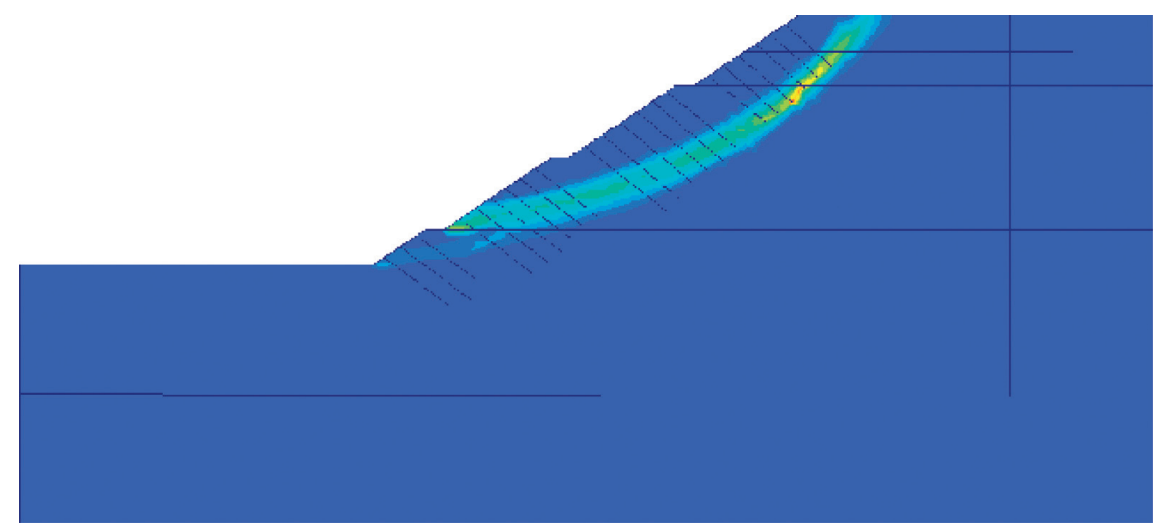

(c)

FIGURE 8: Shear strain increment nephogram of the slope after strength reduction. (a) Working condition 4. (b) Working condition 6. (c) Working condition 8 .

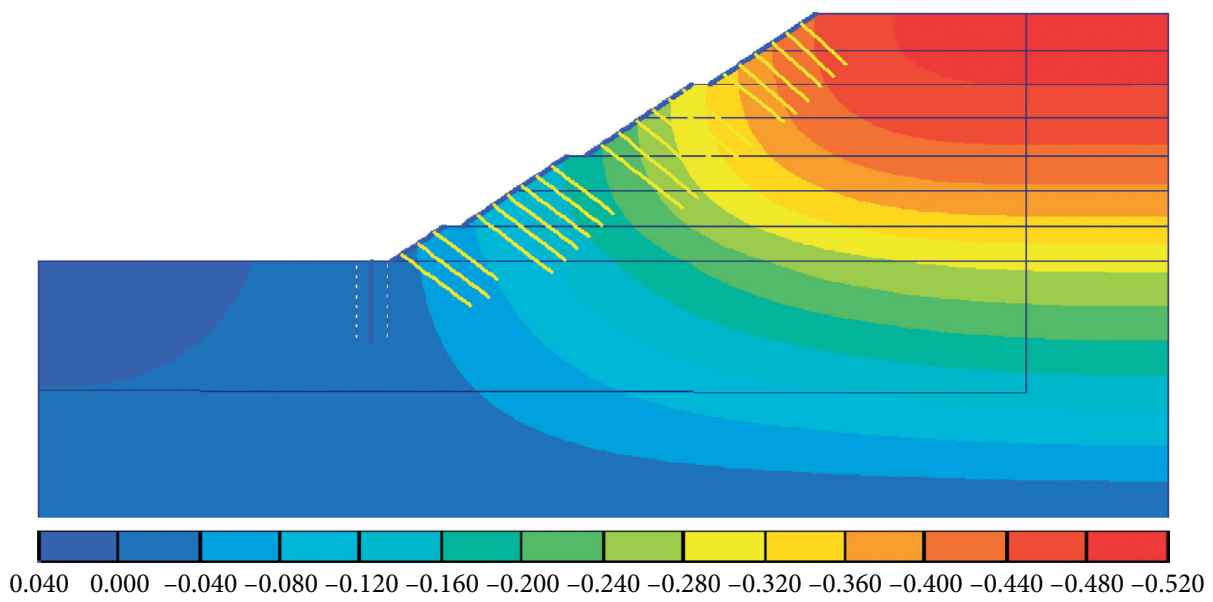

$(\mathrm{m})$

FIGURE 9: Vertical displacement nephogram of slope working condition 8 under reinforcement measures.

2.3.5. Comparison of Slope Sliding Surface Positions during Filling Process between the Reinforcement and Unreinforcement Conditions. As shown in Figure 8(c), the area with large shear strain increment after strength reduction is located at an average of $4.5 \mathrm{~m}$ below the slope surface, which is prone to failure along the sliding surface. The sliding outlet is located roughly at the junction of the first and second slope. As shown in Figure 11. The area with large shear strain increment is transferred to the inner and lower parts, which is located at an average of $11 \mathrm{~m}$ below the slope surface. The sliding outlet is moved to the original foundation below the fill soil. As a result, the reinforcement effect provided a better sliding surface position for the slope.

\section{Analysis of Factors Affecting Stability of Multistage Fill Slopes}

Generally, the stability of the multistage fill slope is complicated. Considering the convenience and safety of construction, it is necessary to take some important internal and external factors of the slope into account [41]. The internal factors are mainly the physical and mechanical parameters of the slope, which include the unit weight, cohesion, and internal friction angle of the slope. External factors mainly include the controllable aspects of man-made construction, that is, slope shape, including ratio of slope, platform width, height of each grade. When the slope engineering geological conditions are certain, each factor has a different degree of influence on its stability, some factors have a greater impact, and some factors have a smaller impact. So, this paper used the sensitivity analysis method to analyze the factors affecting the stability of the multistage fill slope, and the limit equilibrium method is used to solve the safety factor. Besides, the safety factor is used to evaluate the stability of the slope, and the function relationship among the internal and external factors and the safety factor is obtained. Then, the sensitivity coefficient is solved.

3.1. Analysis Methods and Procedures. According to the soil parameters provided by the investigation report of engineering examples, the safety factor is determined by the Morgenstern method [42] of the limit equilibrium method. 


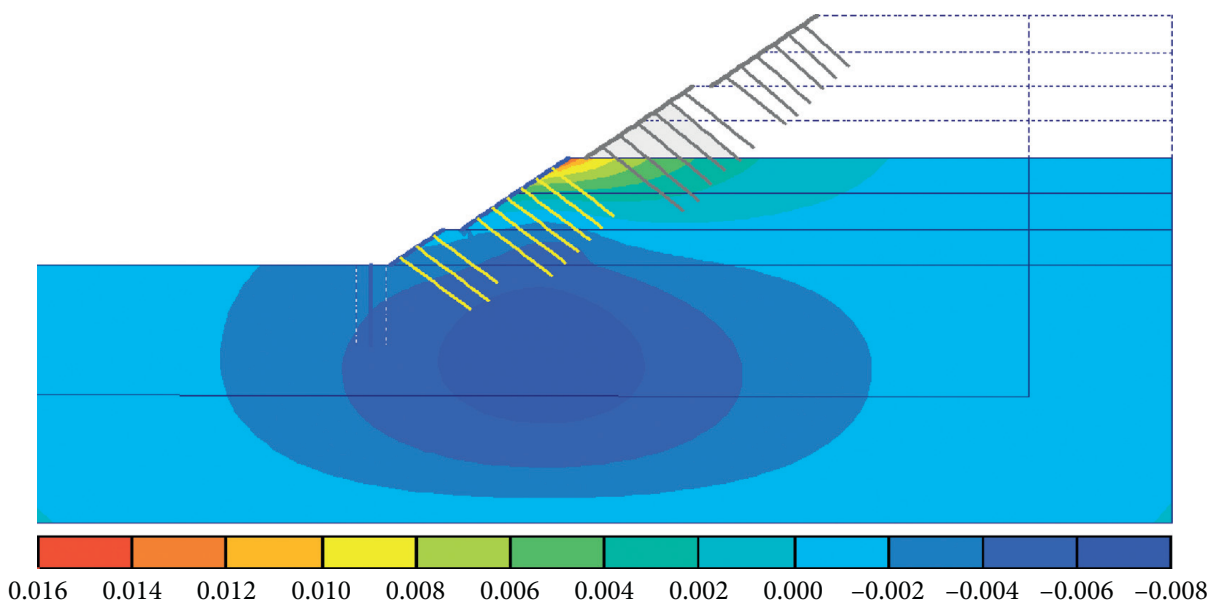

(m)

FIGURE 10: Horizontal displacement nephogram of slope working condition 4 under reinforcement measures.

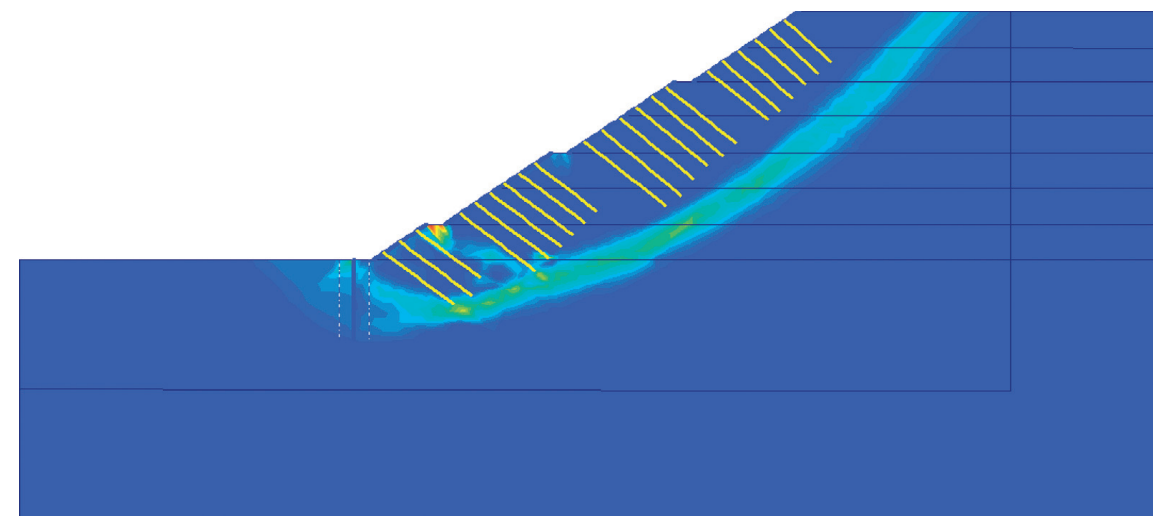

FigURE 11: Shear strain increment nephogram of reinforced slope working condition 8 after strength reduction.

Using the control variable method, the safety factor under the influence of different factors is obtained, and the relationship between each factor and the safety factor is plotted. The sensitivity coefficient of each factor is calculated according to the sensitivity coefficient calculation formula.

Sensitivity analysis [43] refers to the selection of factors that have a greater impact on the indicators of concern from a larger number of uncertain factors. The degree of impact is measured by the sensitivity coefficient. In this study, the formula of sensitivity is shown in formula 1 .

Assume that the function between the safety factor of multistage fill slope and each influencing factor is $F_{s}=\left(X_{1}, X_{2}, \ldots, X_{n}\right)$; then, the sensitivity coefficient of the $X_{n}$ factor is calculated as

$$
S_{n}=\frac{\left|\Delta F_{s n} / F_{s n}\right|}{\left|\Delta X_{s n} / X_{s n}\right|} .
$$

This formula $\left|\Delta F_{s n} / F_{s n}\right|$ is the relative rate of change of the slope safety factor and $\left|\Delta X_{s n} / X_{s n}\right|$ is the relative rate of change of the influencing factors. The value of the sensitivity coefficient $S_{n}$ reflects the influence degree of various factors on the safety factor. The larger $S_{n}$ is, the more sensitive this factor is to the safety factor. Conversely, this factor is less sensitive to the safety factor.

3.2. Impact Analysis Results. As shown in Figures 12 and 13, there is a negative correlation between the unit weight, ratio of slope, height of each grade, and safety factor. However, the relationship between platform width, cohesion, internal friction angle, and safety factor is positively correlated.

The sensitivity coefficient of internal and external factors affecting the stability of multistage fill is obtained by the sensitivity analysis method, as shown in Table 3.

As can be seen from Table 3, the sensitivity coefficient of the internal friction angle is the largest, of which the value is 1.002. And the sensitivity coefficient of the ratio of the slope is the second, of which the value is 0.805 . It shows that the internal friction angle and the ratio of slope have a relatively large influence on the stability of multistage fill slope. In addition, the sensitivity coefficient of platform width is the smallest, of which the value is 0.079 . In a word, the platform width of the slope has the least influence on the stability of the multistage fill slope. The sensitivity coefficient of the height of each grade, unit weight, and cohesion decreased in 


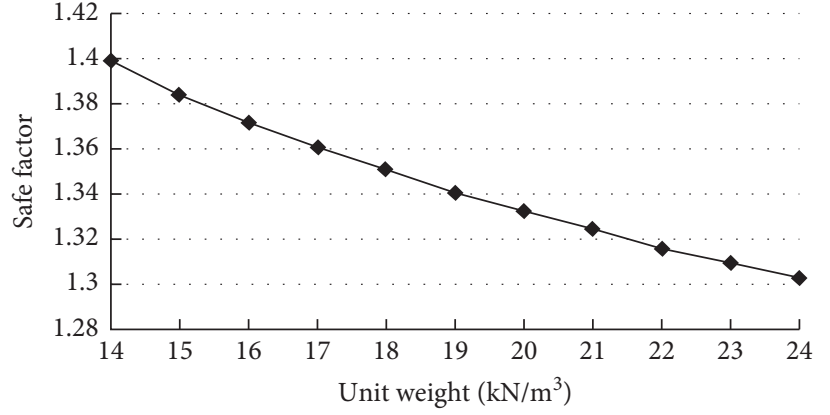

(a)

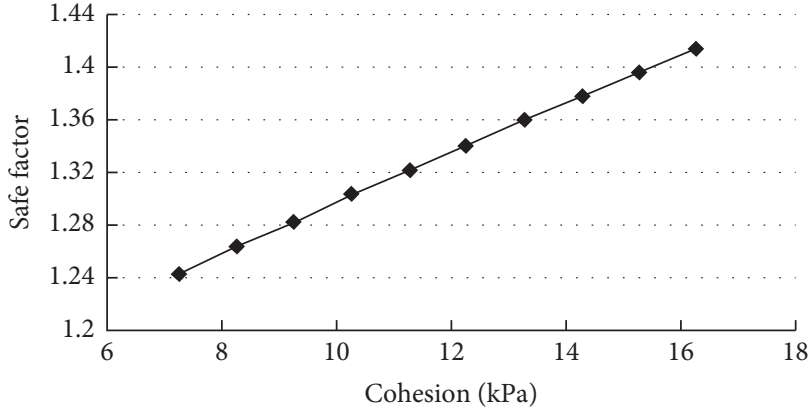

(b)

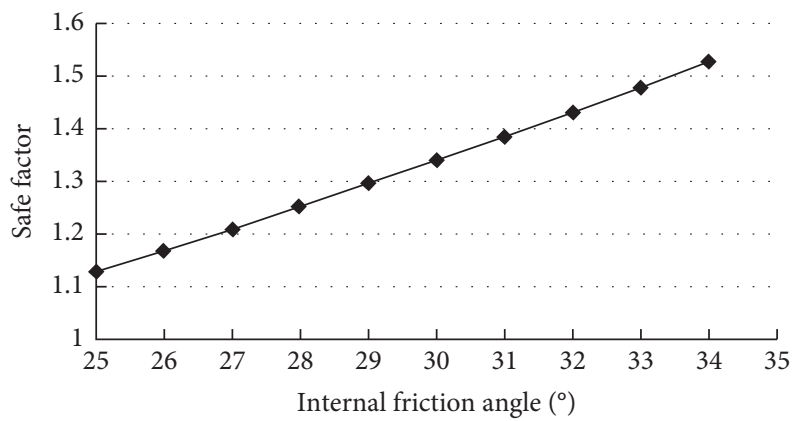

(c)

FIgURE 12: The diagram of the safety factor varies with the internal factors.

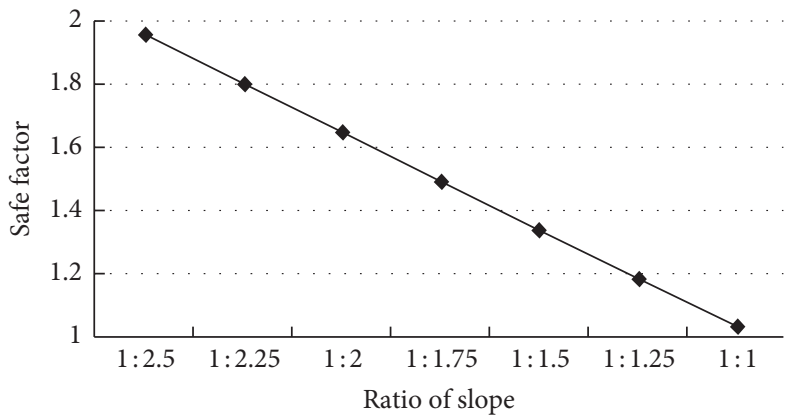

(a)

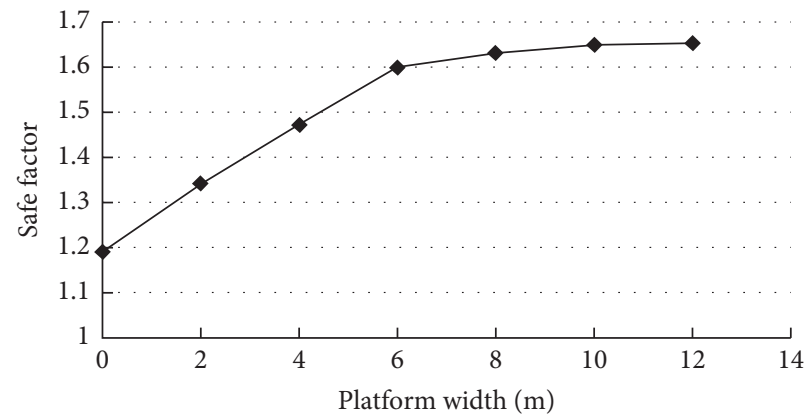

(b)

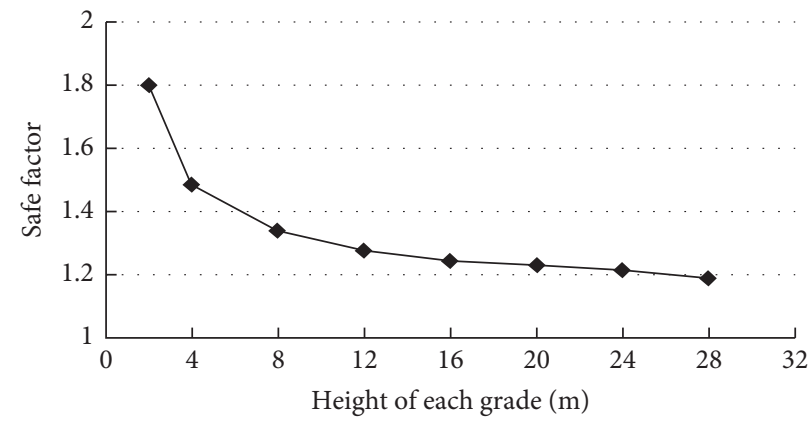

(c)

Figure 13: The diagram of the safety factor varies with the external factors.

TABLE 3: The sensitivity coefficient of influence factors.

\begin{tabular}{lcccccc}
\hline Influence factors & Unit weight & Cohesion & Internal friction angle & Ratio of slope & Platform width & Height of each grade \\
\hline Sensitivity coefficient & 0.179 & 0.172 & 1.002 & 0.805 & 0.079 & 0.252 \\
\hline
\end{tabular}


turn, their values are $0.252,0.179,0.172$, respectively, and they have a relatively small effect on the stability of multistage fill slopes.

\section{Conclusion}

The settlement of the high-filled slope and the instability mechanism were numerically simulated by PLAXIS. The regulation of displacement during the filling process and the change of strain increment before and after reinforcement were summarized. The slope stability is analyzed by the strength reduction method, and the most likely sliding surface of the slope body is obtained. The GEOSTUDIO software is used to calculate the safety factor, and the sensitivity analysis method is used to obtain the sensitivity coefficient of internal and external factors affecting the stability of multistage fill slope. The final conclusions are as follows.

During the filling process of the multistage fill slope, the settlement area is mainly concentrated on the right side of the slope. With the increase of the filling height, the vertical settlement deformation increment of the slope gradually slows down and tends to stabilize. The effect of frame beam anchor reinforcement measures on slope settlement control is very unsatisfactory, but its control on the horizontal displacement of the slope is very impressive. Besides, it can supply the slope with a better sliding surface position. Specifically, reinforcement measures made the sliding surface change from $4.5 \mathrm{~m}$ to $11 \mathrm{~m}$ depth in this model, which means that the depth of the sliding failure surface increases.

Unit weight, ratio of slope, and height of each grade are negatively correlated with the safety factor. At the same time, the platform width, cohesion, and internal friction angle are positively correlated with the safety factor. Among the six factors which were analyzed, the sensitivity coefficient ranges from large to small: internal friction angle, ratio of slope, height of each grade, unit weight, cohesion, and platform width.

For the design of multistage fill slope, the selection of parameters of internal friction angle and cohesion is very significant. When the soil parameters are determined, it is necessary to carefully design the shape of the slope, especially the ratio of slope and the height of each grade. In addition, considering the slope stability and construction process, the platform width should be controlled at about $4 \mathrm{~m}$, and the height of each grade should not exceed $4 \mathrm{~m}$.

\section{Data Availability}

All data used and analyzed during the present study will be available from the corresponding author if deemed necessary.

\section{Conflicts of Interest}

The authors declare that they have no conflicts of interest regarding the publication of this paper.

\section{Acknowledgments}

The authors would gratefully like to acknowledge the support provided by the National Natural Science Foundation of China (nos. 51978177, 41902288, and 51809050), the Science and Technology Plan Project of Guangdong Provincial Department of Transportation (2017-02-018), and the Natural Science Foundation of Guangdong Province (nos. 2018A030313839 and 2016A030310345). The editorial help from Professor Galen Leonhardy of Black Hawk College is also greatly appreciated.

\section{References}

[1] X. Liu, X. Chen, M. Su, S. Zhang, and D. Lu, "Stability analysis of a weathered-basalt soil slope using the double strength reduction method," Advance in Civil Engineering, vol. 2021, Article ID 6640698, 12 pages, 2021.

[2] S.-H. Ye and A.-P. Huang, "Sensitivity analysis of factors affecting stability of cut and fill multistage slope based on improved grey incidence model," Soil Mechanics and Foundation Engineering, vol. 57, no. 1, pp. 8-17, 2020.

[3] C. Sun, J. Chai, T. Luo et al., "Nonlinear shear-strength reduction technique for stability analysis of uniform cohesive slopes with a general nonlinear failure criterion," International Journal of Geomechanics, vol. 21, no. 1, 2021.

[4] J. Pacheco, J. De Brito, C. Chastre, and L. Evangelista, "Probabilistic conversion of the compressive strength of cubes to cylinders of natural and recycled aggregate concrete specimens," Materials, vol. 12, no. 2, 2019.

[5] R. V. Silva, J. De Brito, and R. K. Dhir, "Tensile strength behaviour of recycled aggregate concrete," Construction and Building Materials, vol. 83, pp. 108-118, 2015.

[6] B. Yang and J. Yuan, "Influence of soda content on desiccation cracks in clayey soils," Soil Science Society of America Journal, vol. 83, p. 4, 2019.

[7] W. Yang, L. Neng, W. Xinzhi et al., "Experimental investigation on mechanical behavior and particle crushing of calcareous sand retrieved from South China sea," Engineering Geology, vol. 280, Article ID 105932, 2020.

[8] G. Yang, Z. Zhong, Y. Zhang, and X. Fu, "Optimal design of anchor cables for slope reinforcement based on stress and displacement fields," Journal of Rock Mechanics and Geotechnical Engineering, vol. 7, no. 4, pp. 411-420, 2015.

[9] A. Rajabian, B. V. S. Viswanadham, H. Ghiassian, and H. Salehzadeh, "Centrifuge model studies on anchored geosynthetic slopes for coastal shore protection," Geotextiles and Geomembranes, vol. 34, pp. 144-157, 2012.

[10] C. Chunyi, M. Kun, X. Chengshun, L. Zhimeng, L. Haijiang, and P. Huafu, "Analytical solution for longitudinal vibration of a floating pile in saturated porous media based on a fictitious saturated soil pile model," Computers and Geotechnics, vol. 131, Article ID 103942, 2021.

[11] K. Meng, C. Cui, and H. Li, "An ontology framework for pile integrity evaluation based on analytical methodology," IEEE Access, vol. 8, pp. 72158-72168, 2020.

[12] J. Xiao, W. Qu, H. Jiang, L. Li, and L. Chen, "Fractal characterization and mechanical behavior of pile-soil interface subjected to sulfuric acid," Fractals, vol. 28, no. 6, 2020.

[13] B. Yuan, M. Sun, Y. Wang, L. Zhai, Q. Luo, and X. Zhang, "Full 3D displacement measuring system for 3D displacement field of soil around a laterally loaded pile in transparent soil," International Journal of Geomechanics, vol. 19, 2019. 
[14] J. Zhang, H. Wang, H. W. Huang, and L. H. Chen, "System reliability analysis of soil slopes stabilized with piles," Engineering Geology, vol. 229, pp. 45-52, 2017.

[15] Y. Kim, S. Lee, S. Jeong, and J. Kim, "The effect of pressuregrouted soil nails on the stability of weathered soil slopes," Computers and Geotechnics, vol. 49, pp. 253-263, 2013.

[16] C. Y. Cheuk, C. W. W. Ng, and H. W. Sun, "Numerical experiments of soil nails in loose fill slopes subjected to rainfall infiltration effects," Computers and Geotechnics, vol. 32, no. 4, pp. 290-303, 2005.

[17] C. Li, J. F. Zou, and A. Si-Ga, "Closed-form solution for undrained cavity expansion in anisotropic soil mass based on spatially mobilized plane failure criterion," International Journal of Geomechanics, vol. 19, Article ID 04019075, 2019.

[18] Q. Q. Liu and J. C. Li, "Effects of water seepage on the stability of soil-slopes,” Procedia IUTAM, vol. 17, pp. 29-39, 2015.

[19] R. Yang, Z. Xu, and J. Chai, "Seepage analysis of a multilayer waste slope considering the spatial and temporal domains of permeability," Advances in Civil Engineering, vol. 2019, Article ID 3689097, 10 pages, 2019.

[20] B. Yuan, K. Xu, Y. Wang, R. Chen, and Q. Luo, "Investigation of deflection of a laterally loaded pile and soil deformation using the PIV technique," International Journal of Geomechanics, vol. 17, no. 9, Article ID 04016138, 2016.

[21] B. Yuan, M. Sun, L. Xiong, Q. Luo, H. Li, and S. P. Pradhan, "Investigation of 3D deformation of transparent soil around a laterally loaded pile based on a hydraulic gradient model test," Journal of Building Engineering, vol. 28, Article ID 101024, 2019.

[22] Y. Chen, H. Lin, R. Cao, and C. Zhang, "Slope stability analysis considering different contributions of shear strength parameters," International Journal of Geomechanics, vol. 21, 2020.

[23] Z.-D. Cui, J.-Q. Yang, and L. Yuan, "Land subsidence caused by the interaction of high-rise buildings in soft soil areas," Natural Hazards, vol. 79, no. 2, pp. 1199-1217, 2015.

[24] D. V. Griffiths and P. A. Lane, "Slope stability analysis by finite elements," Géotechnique, vol. 49, no. 3, pp. 387-403, 1999.

[25] M. Lu, H. Jing, B. Wang, and K. Xie, "Consolidation of composite ground improved by granular columns with medium and high replacement ratio," Soils and Foundations, vol. 57, no. 6, pp. 1088-1095, 2017.

[26] C. Sun, J. Chai, B. Ma, T. Luo, Y. Gao, and H. Qiu, "Stability charts for pseudostatic stability analysis of 3D homogeneous soil slopes using strength reduction finite element method," Advances in Civil Engineering, vol. 2019, Article ID 6025698, 18 pages, 2019.

[27] Z. Liang, C. Cui, K. Meng, Y. Xin, H. Pei, and H. Li, "New analytical solutions for longitudinal vibration of a floating pile in layered soils with radial heterogeneity," Mathematics, vol. 8, no. 8, p. 1294, 2020.

[28] E. M. Dawson, W. H. Roth, and A. Drescher, "Slope stability analysis by strength reduction," Géotechnique, vol. 49, no. 6 , pp. 835-840, 1999.

[29] R. Chen, T. Xu, Y. R. Zhao, G. Deng, J. Qiao, and S. Zhou, "Effects of net normal stress on hydro-mechanical behaviour of a kaolinite clay soil under different suction paths," Environmental Geology, vol. 78, no. 710, p. 715, 2019.

[30] S.-H. Jiang, J. Huang, F. Huang, J. Yang, C. Yao, and C.-B. Zhou, "Modelling of spatial variability of soil undrained shear strength by conditional random fields for slope reliability analysis," Applied Mathematical Modelling, vol. 63, pp. 374-389, 2018.
[31] Y. Wang, P. Guo, F. Dai, X. Li, Y. Zhao, and Y. Liu, "Behavior and modeling of fiber-reinforced clay under triaxial compression by combining the superposition method with the energy-based homogenization technique," International Journal of Geomechanics, vol. 18, Article ID 04018172, 2018.

[32] B. Yuan, L. Xiong, L. Zhai et al., "Transparent synthetic soil and its application in modeling of soil-structure interaction using optical system," Frontiers in Earth Science, vol. 7, 2019.

[33] Z. Chang, Q. Cai, L. Ma, and L. Han, "Sensitivity analysis of factors affecting time-dependent slope stability under freezethaw cycles," Mathematical Problems in Engineering, vol. 2018, Article ID 7431465, 10 pages, 2018.

[34] V. Sadarviana, H. Z. Abidin, D. Santoso, J. Kahar, and R. T. Achmad, "Influence of groundwater level to slope displacement by geodetic method," in Proceeding of the 5th International Symposium on Earthhazard and Disaster Mitigation, vol. 1730, AIP Conference Proceedings, Bandung, Indonesia, October 2016.

[35] O. C. Zienkiewicz, C. Humpheson, and R. W. Lewis, "Associated and non-associated visco-plasticity and plasticity in soil mechanics," International Journal of Rock Mechanics and Mining Sciences \& Geomechanics Abstracts, vol. 13, p. 24, 1976.

[36] W. Yi-Xian, G. Pan-Pan, R. Wei-Xin, and B.-X. Yuan, "Laboratory investigation on strength characteristics of expansive soil treated with jute fiber reinforcement," International Journal of Geomechanics, vol. 17, no. 11, Article ID 04017101, 2017.

[37] J. Lv, X. Li, Z. Li, and H. Fu, "Numerical simulations of construction of shield tunnel with small clearance to adjacent tunnel without and with isolation pile reinforcement," KSCE Journal of Civil Engineering, vol. 24, no. 1, pp. 295-309, 2020.

[38] Y. C. Yang, Q. Li, X. Z. Chen, and H. M. Tang, "Discussion on strength reduction using FLAC," Rock and Soil Mechanics, vol. 29, pp. 1103-1106, 2008.

[39] R. Chen, J. Liu, C. W. W. Ng, and Z. K. Chen, "Influence of slope angle on water flow in a three-layer capillary barrier soil cover under heavy rainfall," Soil Science Society of America Journal, vol. 83, no. 6, pp. 1637-1647, 2019.

[40] M. Lu, H. Jing, Y. Zhou, and K. Xie, "General analytical model for consolidation of stone column-reinforced ground and combined composite ground," International Journal of Geomechanics, vol. 17, p. 18, Article ID 04016131, 2016.

[41] D. Wang, R. Zentar, N. E. Abriak, and S. Di, "Long-term mechanical performance of marine sediments solidified with cement, lime, and fly ash," Marine Georesources \& Geotechnology, vol. 36, no. 1, pp. 1-8, 2017.

[42] N. R. Morgenstern and V. E. Price, "The analysis of the stability of general slip surfaces," Géotechnique, vol. 15, no. 1, pp. 79-93, 1965.

[43] Y. Wang, Z. Cao, and S.-K. Au, "Efficient monte carlo simulation of parameter sensitivity in probabilistic slope stability analysis," Computers and Geotechnics, vol. 37, no. 7-8, pp. 1015-1022, 2010. 